\title{
The Balkan tradition in contemporary jazz. Anatoly Vapirov
}

\author{
ALEX VASILIU \\ "George Enescu” National University of Arts Iași \\ ROMANIA*
}

\begin{abstract}
The folkloric character of the beginnings of jazz has been established by all researchers of American classical music. The African-Americans brought as slaves onto the territory of North America, the European émigrés tied to their own folkloric repertoire, the songs in the musical revues on Broadway turned national successes can be considered the first three waves to have fundamentally influenced the history of jazz music. Preserving the classical and modern manner of improvisation and arrangement has not been a solution for authentic jazz musicians, permanently preoccupied with renewing their mode of expression. As it happened in the academic genres, the effect of experiments was mostly to draw the public away, as its capacity of understanding and empathizing with the new musical "products" (especially those in the "free" stylistic area) were discouraging. The areas which also had something original to say in the field of jazz remained the traditional, archaic cultures in Eastern Europe, Asia, the Orient. Compared to folkloric works from very distant areas, the musical culture of the Balkans bears the advantage of diversity, the ease of reception of melodies, rhythms and instrumental sonority. One of the most important architects of ethno-jazz is Anatoly Vapirov. A classically-trained musician, an author of concerts, stage music and soundtracks, a consummate connoisseur of the classical mode of improvisation as a saxophone and clarinet player, Anatoly Vapirov has dedicated decades of his life to researching the archaic musical culture of the Balkans, which he translated into the dual academic-jazz language, in the hypostases of predetermined scored works and of improvised works - either as a soloist, in combos or big bands. This study focuses on highlighting the language techniques, emphasizing the aesthetic-artistic qualities of the music signed Anatoly Vapirov.
\end{abstract}

Keywords: Ethno Jazz, Iancsi Körössy, Richard Oschanitzky, Slavic Jazz, Balkan Jazz.

\section{Introduction}

For several decades, entertainment music, academic genres, jazz have been influenced by folkloric melodies, rhythm and sonority. If, three-four decades ago, lyrical evocative melodic phrases of Asian or Arabic origin displayed at wind instruments, supported rhythmically by percussion instruments from these regions, only illustrated the action musically and the nature images chosen by directors of artistic movies, nowadays the Eastern, Balkan tradition also impacts the recipe of Western-European academic

\footnotetext{
*alexvasiliujazz@gmail.com
} 
compositional style, influences strongly the generating core and the spontaneous creation of jazzmen. It is a reality that is more than half a century old, 1967-2017, it went beyond the limitation of a phenomenon and became a permanence of a culture. I will mention a few milestones in the evolution of the type of music I researched.

We should mention first the Art Ensemble of Chicago, appeared in the first motherland of jazz, mentioned by historians as the experiment of the 1961-'70 decade. Named New Thing, Free Jazz or Avant-garde, the production of this group took again African folklore as a point of reference, similarly to the first jazzmen of late $19^{\text {th }}$ and early $20^{\text {th }}$ centuries, who were the descendents of slaves from the Black continent, brought to North America. However, the relation with traditional African music had been much longer and deeper. Founded in 1966, but named later Art Ensemble of Chicago, the band "used" in their improvisations (that mixed the melodic-rhythmic reminiscences of the first style proper to modern jazz, bop, with almost totally free invention) percussion instruments and short simple melodies belonging to their motherland. From 1966 to 1969 the American and European public got to know the rich instruments, similarly original costumes that represented the ancient African culture. Out of a long series of productions recorded over more than half a century, we may choose examples such as Promenade: Cote Bamako $1^{1}$ (more a performance of local percussion from Mali), Chi-Congo ${ }^{2}$, Toro (an amazing combination of African and Spanish percussion with the modern type of jazz trumpet singing $)^{3}$.

\section{Romanian Ethno Jazz}

Considering the old age of the sonic documents available now, the first important insertions of musical folklore into the language of jazz appeared in Romania. A few years ago, I discovered a series of records from 1956, that were considered lost, of the band conducted by the Romanian pianist of Hungarian origin Iancsi Körössy, born in Cluj in $1926^{4}$. During a public recital with his quartet, the tracks In a hurry and At the Round Dance ${ }^{5}$ were recorded ${ }^{6}$. For a decade, he had been the only Romanian jazzman interested in the

\footnotetext{
${ }^{1}$ The album Urban Bushmen, ECM, 1982.

2 The homonymous album, Decca, 1972.

${ }^{3}$ The album The Spiritual, Freedom, 1972.

${ }^{4}$ He appeared under one given name in the Romanian press and records and under another given name abroad. After moving to North America in 1969, he preferred the form "Jancy".

5 These tracks were issued for the first time on the CD that accompanies the volume Jazz in Romania - Romanian Jazz, vol. I - Jancy Körössy, by Alex Vasiliu (Vasiliu, 2014).

${ }^{6}$ The songs were also recorded by the author with different players in 1967 (Radio Romania) and after 1989 when he came back to his motherland.
} 
folkloric melody, harmonies and rhythm of his native land, and especially in urban folklore.

1969 was the year when the free and ethno styles expanded, bringing colour to the international avant-garde (not only to jazz). It was the year when the album Identification was recorded by the German record company MPS (Most Perfect Sound). The name of the disc, Identification, is important as regards the author-performer's origin and the special elements of the musical language. It was then that the traditional Romanian rhythm-melody entered for the first time the international jazz circuit through the recording of the track The Round Dance from Viziru (Hora de la Viziru), a dance melody chosen by Körössy from the region of Brăila. Reedited several times, this disc is considered to be one of the most important in the world for pianist Körössy's standing, a model in terms of understanding the true principle of the free style, controlled freedom, an original way of adapting the concept of American jazz to specific features of the ethno-cultural region located so far from the motherland of this art.

Resident for more than two decades in the United States of America, Jancy $^{7}$ Körössy allowed the Romanian musical tradition to feed his spontaneous keyboard creations. The last proof of the fortunate relations with American jazz, of the impressionistic and post-Romantic academic perspective, of the Romanian methods of composing a musical discourse was a series of solo piano records made in Atlanta, U.S. in 1975, and released 38 years later on a double $\mathrm{CD}^{8}$.

Starting with 1967, several important Romanian jazzmen became interested in musical tradition. That year, Richard Oschanitzky recorded three tracks: two with melodic motives invented by him in the folkloric style Rustica, Dans ${ }^{9}$ - and one inspired from the folk tune Pe deal pe la Cornățel (On the Cornăţel Hill) ${ }^{10}$. As a jazz musician, Richard Oschanitzky was most sensitive to the melodic, rhythmic and sonic resources of folklore. From 1967 to 1968 he went through a first phase of the relation between folklore and jazz by displaying the original theme on a swing rhythm and developing the improvisation in the style of American jazz while maintaining the harmonic cipher that did not betray the initial melodic motive.

In 1969 Richard Osxhanitzky passed to a second phase of inventing melodic motives in the style of Szekely (Hungarian) and Romanian archaic

\footnotetext{
${ }^{7}$ Having settled in North America, the musician adapted his given name to his adoptive homeland.

${ }^{8}$ American Impressions and Romanian Landscapes, 7 Dreams Records. 7D-113. 2013.

${ }^{9}$ Radio Romania recordings edited in the series Romanian Jazz Masters on the double CD Memorial Richard Oschanitzky vol. I, 7 Dream Records, 2006.

${ }^{10}$ A recording from 1967, edited on the disc Jam Session with Friedrich Gulda, Jazz Series no. 5, Electrecord, EDD 1180, 1968.
} 
folklore, by preserving the novel rhythmic bases, the spontaneous improvisations in bop and free styles. Oschanitzky's originality in relation to the creations of combo Art Ensemble of Chicago and of pianist Vagivmustafa Zadeh, to which he listened to when these albums appeared $(1966,1968)$, grew by multiplying the sonic sources up to the breadth of the big band as in the tracks Procession or Neurasia ${ }^{11}$. Oschanitzky's inclination towards archaic music may be explained by the fact that he studied it rigorously at the Conservatory under the guidance of composer and professor Mihail Jora, who also supported orienting the creator towards rural, authentic folklore, and by the empathy with the compositional principles of Béla Bartók.

The third and most complex phase in the development of the folklorejazz relation in Richard Oschanitzky's creation meant the inclusion of Arabic, Chinese, Romanian melodic samples in a musical mixture that also featured the Viennese waltz, the classical academic type of writing for a symphonic orchestra, and the jazzy spontaneous melodic invention obviously not written in a score. The last two stages meant paths opened by the Romanian composer towards world music, a universe so familiar today, and towards the hard terrain of symphonic jazz through the Toccata for piano and jazz septet (1966), the Double concerto for piano, tenor saxophone, symphonic orchestra and big band (1969) and the (Mountain) Variations '71, composed and recorded in 1971.

Most Romanian jazzmen chose local traditional music as a source of inspiration, with their works being documented in radio recordings, such as the Quintet of Bucharest (Radio Romania, 1973), and especially on discs. Johnny Răducanu, Marius Popp, Ramon Tavernier, Harry Tavitian (I only quoted a few names) represent various ways of combining the two traditions - jazz and (Romanian, Armenian, Balkan) folklore. As the overview of Romanian ethno jazz history cannot feature all important achievements, I shall conclude with Nicolas Simion, a saxophonist and composer who released many recordings from festivals, clubs and concerts at his own record company 7 Dream, pianist and composer Lucian Ban, the first Romanian musician on the discography of the prestigious German label ECM, the Arifa trio - cultivating exclusively the ethno genre by combining Eastern European and Balkan traditions with elements of academic contemporary music. The advantage of this small group in mapping a vast ethno-cultural territory lies in the diversity of musical education and experience of clarinet player Alex Simu (Romania), Sjahin During (Turkey - the Netherlands) playing African and Anatolian percussion, and German pianist Franz von Chossy. In order to broaden the area of the ancient tradition they are exploring, in 2014 the members of the trio started the

\footnotetext{
${ }^{11}$ Radio Romania recordings from 1970, released in the series Romanian Jazz Masters on the double CD Memorial Richard Oschanitzky, vol. I, 7 Dream Records. 2006.
} 
project Arifa and Eastern Voices by adding to the sound sources of the initial band (bass clarinet, piano, percussion of different types) three female voices from China, Iran and Bulgaria, with the singers enriching in their turn the musical sound spectrum by handling ancient instruments from the countries mentioned above.

\section{Slavic jazz - Anatoly Vapirov}

In another placed under a communist regime, Poland, melodies from peasant folklore were quoted in the works of authors and improvisers retained not only in their country but in the entire history of jazz. I am referring to Andrzjey Trzaskowski, Zbignew Namislowski and Krzystof Komeda - the latter, best known in the jazz and cinema environments of the United States of America, considered to be the first one who conferred personality to European and not only to Polish jazz. It is interesting to note: this achievement did not occur in a country accustomed as early as the 1930s with the most important American jazzmen due to radio and very successful concerts and discs (France, England, Italy, Germany, the Netherlands, Sweden) but in areas where the rural, especially the ancient, musical tradition survived. The general Slavic melancholy melodic profile, the poetically sad character of Polish songs found their way into the jazz creations in the early 1960s in the recordings of trumpet player Tomas Stanko and especially of composer and pianist Krzystof Komeda.

Also halfway through the 1961-1970 decade, jazzmen learnt about a pianist and composer who combined modern harmonies, the post-bop improvising style with the melody and rhythm of Azerbaijan. The two contrasting modes, shur (melancholy, sadness) - rast (joy) found their temperately modern expression in the already highly ornate pianistic production of Vagivmustafa Zadeh, as the relation of blues and modern jazz with the Azeri mugham turned a successful artistic couple. His daughter, nowadays a headline of festivals and concerts hosted by prestigious stages, pianist and singer Aziza Mustafazadeh has enriched and refined the fusion of mugham with modern jazz by adding to improvisations "particles" from the classical vocal culture and from jazz-rock.

One of the musicians who have been arguing for four decades for the ability of the musical language of Central and Eastern Europe to influence the ways of expression in jazz is Anatoly Vapirov. Born in the Ukraine, in Berdiansk, on 24 November 1947, Vapirov studied clarinet, saxophone and composition at the Conservatory of Sankt Petersburg, later graduating the course of big band conducting. His musical background in the academic genres and the talent to improvise gave him early on the possibility to express himself dually: in jazz as a player of tenor, alto and soprano saxophone, and in the area 
of academic music as a player of clarinet and bass clarinet and an author of chamber, concert and vocal-symphonic works ${ }^{12}$.

Almost all his creations in these genres are influenced by the Balkanoriental and Russian musical tradition. The first explanation of Anatoly Vapirov's way to feel and create music in the entirety lies in double ascendency: his father was Bulgarian and his mother Russian. Growing up and developing as a musician in the first part of his life, up to the age of 40 , in the Ukranian ethno-cultural space, in which the oriental, Hungarian, Romanian and Russian traditions mingle, Anatoly Vapirov brought to original spontaneous variations and compositions traditional melodic, harmonic, rhythmic elements belonging to an area studied at the beginning of the $20^{\text {th }}$ century by ethnologist and composer Béla Bartók.

The second layer of the musical-spiritual climate in Vapirov's music is represented by the Russian, Slavic emotional model, that poetic melancholy present in the creations of Tchaikovsky, Rahmaninov, Stravinski and Shostakovici, to name only four well-known composers. The strings of musician Anatoly Vapirov's sensitiveness were tied even tighter when he moved to his father's native Bulgaria, as the Balkan tradition marked even more almost all of his written and improvised works for small bands (combo), ensembles (symphonic orchestra and big band) or for one player (Vapirov).

The third layer comes from North America and represents jazz in three main hypostases - blues matching the oriental-Russian melancholy, bop favouring the imagination in improvisation and the modern-type virtuoso instrumental technique, impressive in rapid tempos, with the free style proving that the musician understands the total melodic-harmonic-rhythmic-expressive freedom only as a corollary of the bank of ideas, of the incandescent internal combustion, which all complete the dual traditional-modern form of an artistic event.

As always, the artist melts his personal life experiences into his art. The fourth explanation of the constitutive drama in Anatoly Vapirov's music lies in the story of his life, the main coordinates being his long-lasting search for his sister, who had disappeared during World War II and the years of imprisonment due to a conflict with the Soviet authorities. The latter layer was revealed to me by the musician during a conversation occasioned by his first presence at the International Jazz Festival "Richard Oschanitzky" that I

\footnotetext{
12 We may mention Macbeth for tenor saxophone and chamber orchestra (The Orchestra of the Mali Opera and Ballet Theatre, soloist and conductor Anatoly Vapirov); Lines of Destiny (dedicated to Alban Berg) for tenor, alto, soprano saxophones, bass clarinet and string quartet, Leningrad 1985; Concerto grosso for symphony orchestra and jazz quartet (Orchestra of the Ruse Philharmony, Anatoly Vapirov, Iuri Kuzneţov, Stoian Iankulov, Dimităr Şanon), Ruse 2000.
} 
organized with the support of the Iaşi division of the National Television of Romania.

To exemplify his constant interest in musical folklore, I will comment on a series of his recordings representing over four decades. The album Ucracia, released in 1976 together with the Jazz Ensemble of Leningrad, sheds light right from its title and the first notes of the melodic theme on an ethno-cultural area of the Ukraine that inspired the composer and the improvisers. Including the Ukranian and Romanian Maramureş, the area is illustrated through the spontaneous melodic line produced by Anatoly Vapirov on soprano saxophone, with a timbre similar to the tárogató. Called zurna, this instrument was brought by the Turks in the Middle Ages from the Middle East to Eastern Europe, acquiring the name of Turkish flute, in Hungarian töröksip or tárogató, where the Romanian name taragot came from. The work that opens the discographic album Ucracia has two-fold traditional melodic aspects representing the Romanian and Hungarian folklore, convincingly expressed by Anatoly Vapirov on soprano saxophone (replacing the tárogató). Vapirov's interpretation on the saxophone and the double bass solo remind one of a traditional Szekely song arranged by the Romanian Richard Oschanitzky in his free jazz work Procession (Radio Romania - 1970, Double cd Romanian Jazz Masters. Memorial Richard Oschanitzky vol. I, 7 Dream Records - 2006). The difference between the two works lies in the fact that the soprano saxophone and double bass solos are longer on the disc Ucracia, Vapirov having the time to adorn with opulence the traditional melody with ornaments runs stressing the specificity of the area ${ }^{13}$. It is important to note that medium, rapid and ultra-rapid tempo ornaments, especially on soprano saxophone, are a brand of the improvisational style, present in all his creations.

By placing the modern monodic performance before the Orthodox tradition of the male choir, followed by the tenor saxophone solo combining traditional elements from the area with the free jazz-type improvisation, Anatoly Vapirov was establishing in 1980 through his album Mysteria - a dangerous link between the Ukranian folklore and the radical style of free modern jazz. The link was all the more dangerous in the 1980s of a certain political intransigence of the Soviet authorities, when the rhythmic-melodic elements of a march are inserted parodically over the course of the ample work.

The relation archaic tradition - instant composing (with or without jazz elements) is impressively illustrated by Anatoly Vapirov when he has as a partner a percussionist (on stage or in a studio) using an entire set of instruments of this kind. On 20 May 2005 Vapirov took part for the second time in the International Festival "Richard Oschanitzky" in Iaşi, Romania,

\footnotetext{
${ }^{13}$ Radio Romania - 1970, Double cd Romanian Jazz Masters. Memorial Richard Oschanitzky vol. I, 7 Dream Records - 2006.
} 
playing together with Vladimir Tarasov. The communication between the two musicians was impressive. The matching between Tarasov and Vapirov in the context of this study was expressed when Vapirov played on the tenor saxophone the melodic line perfectly resembling the traditional Romanian song doina. The ornaments of the Vapirov label became one with the traditional Romanian melody - an outstanding achievement as Anatoly Vapirov told me that he had never listened to Romanian folklore. As an example, Vladimir Tarasov's kettle-drum is not merely a rhythmic supporter but comments on Vapirov's melodic discourse by offering ideas, as his instrument also has subtle melodic-expressive qualities.

The archaic aspect of the music in the case of the sonic sources wind instrument-percussion is achieved especially when Anatoly Vapirov improvises on soprano saxophone. As I have mentioned, the timbre of this instrument is similar not only to that of the tárogató but also to Asian and Arabian instruments, the sonic image being completed by the drums skillfully handled by Vladimir Tarasov.

The guiding lines tracing the ethnographic regions of Turkey, Bulgaria and Hungary, mentioned earlier, have always influenced the creation of Anatoly Vapirov. In 2002, at the International Festival he organises in Varna, Anatoly Vapirov improvised on the same soprano saxophone together with guitarist Enver Izmailov and percussionist Kornel Horvath, providing a synthetic picture of the nostalgic, evocative transfigured melodics, much like the sonority of the percussion in a modern, urban landscape.

\section{Conclusions}

An excellent improviser in the style of the American saxophonists who have authored modern improvisational concepts, the Russian/Bulgarian Anatoly Vapirov has not only added to the melting pot of contemporary jazz exotic ingredients from the areas where he has been living. He has proved the viable togetherness of the two traditional, folkloric musical cultures, contributing to the renewal of jazz, helping tradition to assert itself in the forms of contemporary music. His predetermined or spontaneous achievements represent a defining stage in the history of modern jazz.

We should acknowledge that a large number of festivals initiated many years ago as events of American jazz proved openness towards the elements of old folklore from various countries. These meetings gradually became world music festivals in which an increasingly large number of performers and singers from Europe, Asia, Latin America, the Middle East have been cultivating the melting pot which is so appreciated today, in which the blues, swing, improvisation, the sounds of instruments typical of American jazz mingle with the intonations, ornaments, rhythmic accents, novel timbres of the instruments in the area under discussion. The free movement of information, 
the presence of samples of this type of music, rich in exotic traditions, in the media, feature films, documentaries, multimedia theatre performances have already caused the public to become accustomed to the musical productions, which seemed foreign or exotic before. Ethno jazz and world music are two original sonic-artistic facets rich in musical ideas, in instrumental aspects that are worth researching.

\section{References}

Davis, F. (1990). Outcats. Jazz composers, Instrumentalists and Singers. Oxford University Press.

Gridley, M. (2000). Jazz History and Analysis, ed. VII. New Jersey: Prentice Hall, Inc. Englewood Cliffs.

Körössy, J. (2013). American Impressions And Romanian Landscapes. 7 Dreams Records. 7D-113.

Vapirov, A. \& Kuznetsov, Y. (Recorded Live 1997/1998) Bridge Over Sea. AVA Records 007.

Vasiliu, A. (2014). The Works of Richard Oschanitzky: Stylistic features. Frankfurt: Peter Lang.

Vasiliu, A. (2015). Jazz în România - jazz românesc: Jancy Körössy [Jazz in Romania - Romanian jazz: Jancy Körössy]. Iaşi: Editura Artes.

Tavitian, H. \& Vapirov, A. (2007). Dancin' 'round The Black Sea. Pirate Records 005. Wagner, J. (1992). Guide du Jazz. Invitation a l'histoire et l'esthétique du jazz. Paris: Syros/Alternatives.

(2006). Memorial Richard Oschanitzky, I. Romanian Jazz Masters. Radio România 1970: 7 Dream Records. 